\title{
The Portuguese version of the Body Image Scale (BIS) - psychometric properties in a sample of breast cancer patients
}

\author{
Helena Moreira ${ }^{\mathrm{a}, \mathrm{b}, *}$, Sónia Silva ${ }^{\mathrm{a}, \mathrm{b}}$, Andreia Marques ${ }^{\mathrm{a}}$, Maria Cristina Canavarro ${ }^{\mathrm{a}, \mathrm{b}}$ \\ ${ }^{a}$ Faculty of Psychology and Educational Sciences, University of Coimbra, Rua do Colégio Novo, Apartado 6153, 3001-802 Coimbra, Portugal \\ ${ }^{\mathrm{b}}$ Psychological Intervention Unit (UnIP) of Coimbra University Hospitals, Dr. Daniel de Matos Maternity, Rua Miguel Torga, $3030-165$ Coimbra, Portugal
}

Keywords:

Body image scale

Instrument

Body image

Cancer

Portuguese version

EORTC

Breast cancer

\begin{abstract}
A B S T R A C T
Purpose: The aim of this study was to analyse the psychometric properties of the Portuguese version of the body image scale (BIS; Hopwood, P., Fletcher, I., Lee, A., Al Ghazal, S., 2001. A body image scale for use with cancer patients. European Journal of Cancer, 37, 189-197). This is a brief and psychometric robust measure of body image for use with cancer patients, independently of age, cancer type, treatment or stage of the disease and it was developed in collaboration with the European Organization for Research and Treatment of Cancer (EORTC) Quality of Life Study Group.

Method: The sample is comprised of 173 Portuguese postoperative breast cancer patients that completed a battery of measures that included the BIS and other scales of body image and quality of life, in order to explore its construct validity.

Results: The Portuguese version of BIS confirmed the original unidimensional structure and demonstrated adequate internal consistency, both in the global sample $(\alpha=.93)$ as in surgical subgroups (mastectomy $=.92$ and breast-conserving surgery $=.93$ ). Evidence for the construct validity was provided through moderate to largely sized correlations between the BIS and other related measures. In further support of its discriminant validity, significant differences in BIS scores were found between women who underwent mastectomy and those who underwent breast-conserving surgery, with the former presenting higher scores. Age and time since diagnosis were not associated with BIS scores. Conclusions: The Portuguese BIS proved to be a reliable and valid measure of body image concerns in a sample of breast cancer patients, allowing a brief and comprehensive assessment, both on clinical and research settings.
\end{abstract}

(c) 2009 Elsevier Ltd. All rights reserved.

\section{Introduction}

Cancer and cancer treatment can have a profound impact on a patient's physical appearance (Frith et al., 2007; Rumsey and Harcourt, 2005). For the majority of patients, appearance changes (e.g. hair loss, loss of a member through amputation) are very distressing and often even more difficult to cope with than other secondary symptoms such as nausea or vomiting (White, 2002).

Body image is an important component of a cancer patient's quality of life (QOL) (DeFrank et al., 2007; Hopwood et al., 2001), having a relevant role on their adjustment to the disease (Helms et al., 2008; Hormes et al., 2008). Although there is not yet a clear definition of body image in psycho-oncology (White, 2000), the

\footnotetext{
* Corresponding author. Linha de Investigação Relações, Desenvolvimento e Saúde, Instituto de Psicologia Cognitiva e Desenvolvimento Vocacional e Social (IPCDVS), Faculdade de Psicologia e Ciências da Educação, Universidade de Coimbra, Rua do Colégio Novo, Apartado 6153, 3001-802 Coimbra, Portugal.

E-mail address: helena.tcmoreira@gmail.com (H. Moreira).
}

most recent perspectives that have emerged in the mainstream body image literature consider this to be a multidimensional construct that encompasses cognitive, affective and behavioural components (Cash and Pruzinsky, 1990, 2002; Jakatdar et al., 2006).

A considerable amount of research has been focused on body image among cancer patients, particularly, on women with breast cancer (e.g. Carver et al., 1998; Moyer, 1997). For example, many studies have explored the impact of surgery on women's adjustment and QOL, reporting few or no difference between breastconserving surgery (BCS; the surgery in which only the tumor and some surrounding tissue is removed, therefore preserving as much of the shape and size of the breast as possible) and mastectomy (i.e. the surgery in which the whole breast is removed) (e.g. Ganz et al., 1992a; Janz et al., 2005; Moyer, 1997; Poulsen et al., 1997). The only difference between surgeries appears to be on body image and sexual functioning, as patients treated with mastectomy report more concerns with appearance and more sexual difficulties than those treated with BCS (e.g. Bloom et al., 2007; Fallowfield et al., 1986). 
Although a large number of studies have been developed in this area, there are only a few measures available to assess body image among cancer patients. The majority of studies have been using instruments developed for use on the general population and even though some of them can be applied to cancer patients with a few minor modifications (White, 2002), such as the Appearance Schemas Inventory - Revised (Cash et al., 2004) which assesses appearance investment, the majority are not appropriate for measuring appearance issues among this specific population, lacking the sensitivity and specificity needed to cover important areas of concern among cancer patients.

Cancer-related appearance issues have also been assessed through body image subscales or items of cancer global measures of QOL (for a review see Victorson et al., 2007). These instruments, despite the advantage of being specifically designed for persons with cancer and thus being sensitive to difficulties related to surgery and cancer treatments, are too general and usually include only a few items to evaluate body image concerns. One example is the European Organization for Research and Treatment of Cancer Quality of Life Questionnaire Breast Cancer Module (EORTC QLQ-BR23), the module designed for breast cancer that is used in conjunction with the EORTC Quality of Life Questionnaire (QLQ-C30) (Aaronson et al., 1993), both developed by the Quality of Life Study Group from the EORTC. The subscale of body image is comprised of four items and covers topics such as body satisfaction or feelings of physical attractiveness. Another example is the Cancer Rehabilitation Evaluation System CARES (Ganz et al., 1992c), which also has three items assessing embarrassment and discomfort with one's body and its changes.

Among the existing body image assessing instruments in oncology, some were designed to measure only a particular domain of body image, such as the measure of body apperception (MBA), developed by Carver et al. (1998), to assess appearance investment, i.e. to what extent women with breast cancer base their self-esteem on their body image. Others, although more comprehensive, are lengthy, thus imposing limitations on their applicability. One example is the Body Image After Breast Cancer Questionnaire (BIBCQ), developed by Baxter et al. (2006), with the purpose of thoroughly measuring the long-term impact of breast cancer on several dimensions of body image. However, its extension (45 items) does not make its use easy in clinical and research contexts.

Considering this, it is clear that a brief and psychometric robust instrument, applicable to all cancer patients, independently of age, cancer type, treatment or stage of the disease is needed to assess body image, both in clinical and research settings. The body image scale (BIS), developed by Hopwood et al. (2001) fulfils these criteria, allowing a complete yet brief assessment of behavioural, affective and cognitive aspects of body image and is also sensitive to typical areas of concern for cancer patients. The development of this instrument followed similar guidelines to those recommended by the Quality of Life Study Group from the EORTC for questionnaire module development (Sprangers et al., 1993) and was designed to be used along with the QLQ-C30 or other QOL measure, complementing QOL assessment in clinical trials or psychosocial research. Four of its 10 items comprise the body image subscale of the QLQ-BR23 module. The scale was validated among breast cancer patients and has revealed good psychometric properties, proving to be an adequate and valid measure of body image among this population (Hopwood et al., 2001). According to the authors, it is also applicable across several types of cancer and treatment situations.

In Portugal, there is not any validated measure of body image that is specifically designed for cancer patients, thus limiting research in this area. Therefore, this study was conducted to analyse the psychometric properties of the Portuguese version of the BIS among a sample of breast cancer patients. In particular, it aims to: (1) examine the Portuguese BIS factor structure; (2) analyse its reliability; (3) explore its construct validity; and (4) analyse the relationship between the BIS, the patient's age and the length of time since diagnosis.

To demonstrate construct validity, hypotheses about the association between the BIS and related measures were formulated and tested. Particularly, a largely sized relationship was hypothesized between the BIS and other related measures of body image (such as the DAS24, the body shame subscale and the body image WHOQOL facet). Relationships of a medium effect were expected between the BIS and appearance investment and QOL.

It is also expected that patients treated with mastectomy present higher scores on BIS than those treated with BCS. Finally, we expect a moderate association between the BIS scores, age and time since diagnosis.

\section{Methods}

\section{Participants and procedure}

The sample is comprised of 173 postoperative breast cancer patients, participating in a broader study of psychosocial adjustment carried out by the Psychological Intervention Unit (UnIP) of Coimbra University Hospitals (CUH) in the Gynaecologic, Radiotherapy and Chemotherapy departments of this hospital. A group of participants were also recruited from the Reach to Recovery Association (specifically the one based in the central region of the country), a voluntary organization formed by breast cancer survivors who help other women confronting the same disease. Criteria for inclusion in this study consisted of having been diagnosed with non-metastatic breast cancer, having done breast surgery (BCS or mastectomy), having no other major disabling medical or psychiatric condition, being female, being able to read and write Portuguese and being at least 18 years old.

Ethical approval was obtained from the CUH Research Ethics Committee and from the board director of the Reach to Recovery organization. Detailed explanation of research objectives and of confidentiality requirements were given to all participants and informed consent was obtained from all, prior to the completion of the battery of questionnaires.

Patients recruited in the Radiotherapy and Chemotherapy departments of CUH were invited to participate in the study before or during their treatment $(n=69)$ and those recruited in the Gynaecologic department were hospitalized for breast reconstruction surgery or oophorectomy $(n=48)$. An envelope containing an explanatory letter and self-report measures was given to participants, who later returned it personally to the researcher. The clinical data was obtained from the patients' medical records. Participants from the Reach to Recovery association were volunteers collaborating with this organization or women who went to the association to acquire a prosthesis or related material $(n=56)$. The envelope containing the explanatory letter and the selfreported measures was handed to all participants who later returned the questionnaires in a postage-paid, pre-addressed envelope. The clinical data was self-reported by respondents.

\section{Measures}

\section{Body image}

The body image scale [BIS] (Hopwood et al., 2001) is a 10 item measure developed to briefly and comprehensively assess affective (e.g. feeling self-conscious), behavioural (e.g. difficulty at looking at the naked body) and cognitive (e.g. satisfaction with appearance) dimensions of body image in cancer patients and has been designed to use with any cancer or the treatment thereof. It uses a 4-point response scale $(0=$ not at all to $3=$ very $m u c h)$ and the final score is the sum of the 10 items, ranging from 0 to 30 , with zero scores representing no symptom or distress and higher scores 
corresponding to increasing symptoms and distress or more body image concerns. Although in the preliminary version of the scale five questions were presented positively, after the initial field testing the authors decided to redraft the scale and present all items negatively in order to avoid some possible discomfort in responding to the positively phrased items (e.g. Have you been feeling feminine/ masculine?). The original version revealed a single-factor solution and demonstrated good psychometric characteristics, with adequate reliability (Cronbach's alpha $=.93$ ) and adequate validity.

The Portuguese version of the BIS was developed through a forward-backward translation procedure, according to the recommendations for translating questionnaires of the Quality of Life Group of the EORTC (Cull et al., 2002). The authors of the Portuguese version, native speakers of Portuguese, with a high level of fluency in English, independently translated the 10 items of the English version of BIS. Both translated versions were then compared and, after discussing and analysing its similarities and differences, the first Portuguese version was obtained. An English native speaker subsequently translated the preliminary Portuguese version back to English, without reference to the original. Finally, the two versions (the original and the backtranslated) were compared and translation difficulties were analysed and resolved between translators, in order to attain a comprehensible instrument, conceptually consistent with the original.

When translating and adapting this instrument, the specific Portuguese culture and language was taken into account. Although always maintaining the consistency with the original scale, some expressions or phrases were slightly altered in order to be totally understood by the Portuguese patients.

The preliminary Portuguese version was administered to a pilotgroup of 15 breast cancer patients in order to identify and solve any potential problem in translation. After completing the questionnaire, patients were asked about each item (e.g. if it was difficult to understand, confusing, upsetting or offensive in any way, and appropriate to their experience). In general, patients showed a good understanding of items and no major difficulties in responding to the questionnaire were reported. The final Portuguese version of BIS was then attained (See Appendix 1).

\section{Measures of body image and quality of life}

The following measures were used to analyse the construct validity (convergent and discriminant) of the Portuguese BIS:

\section{Appearance investment}

The Appearance Schemas Inventory - Revised [ASI-R] (Cash et al., 2004; Portuguese version: Nazaré et al., in press) was used to assess appearance investment, which is a central dimension of body image concerning the assumptions about the significance and effects of appearance in one's life. The Portuguese version followed translation requirements and revealed good internal consistency and appropriate construct validity (Nazaré et al., in press). As the original scale, it has 20 items, using a 5-point scale $(1=$ strongly disagree to $5=$ strongly agree) and has two-factors: (1) the self-evaluative salience (SES) subscale assesses the individual's belief in how their appearance influences their self-worth and self-concept (12 items); and (2) the motivational salience (MS) subscale measures the individual's efforts to be or feel attractive (eight items). In this sample, Cronbach's alphas were .76 for the SES and .73 for the MS subscales.

\section{Self-consciousness of appearance}

To assess levels of self-consciousness of appearance or, in general, the discomfort and inhibition with appearance, we used the Derriford Appearance Scale 24 [DAS24] (Carr et al., 2005; Portuguese version adapted by Moreira and Canavarro, in preparation), the 24-item short form of the original DAS59 (Carr et al., 2000). The Portuguese version was developed through a back-translation technique and, as the original measure, it includes 10 items which are rated from 1 (lowest distress) to 4 (highest distress) and 14 items which are rated from 0 (not applicable) to 4 (highest distress). The final score can range from 10 to 96, with higher scores indicating more distress with appearance. Cronbach's alpha in this sample was .80 .

\section{Body shame}

The body shame subscale of the Experience of Shame Scale [ESS] (Andrews et al., 2002; Portuguese version adapted by Moreira and Canavarro, 2008) was used. It has four items, rated on a 4-point scale ranging from 1 (nothing) to 4 (very much), and requires that the respondent selects the option that best express the intensity with which they experienced each item in the last 3 months (e.g. Have you avoided looking at yourself in the mirror?; Have you worried about what other people think of your appearance?). Cronbach's alpha in this sample was .84 .

\section{Quality of life}

To measure the individual's subjective perception of QOL, we used the Portuguese version of the World Health Organization Quality of Life - bref [WHOQOL-Bref] (WHOQOL Group, 1998a,b; Portuguese version: Vaz Serra et al., 2006). This instrument was validated for the Portuguese population according to guidelines of the WHOQOL group and presented good reliability and validity (Vaz Serra et al., 2006). It is comprised of 26 items providing scores for four domains, each one including several specific facets: physical (e.g. pain/discomfort, sleep and rest), psychological (e.g. positive feelings, body image, self-esteem) social relationships (e.g. social support, sexual activity) and environment (e.g. physical environment, financial resources), including a facet of the overall QOL (general QOL and general health). It employs a 5-point scale, with higher scores indicating higher QOL. Cronbach's alpha ranged, in this sample, from .70 and .85 between domains.

\section{Statistical analyses}

Descriptives were obtained for all demographic and clinical characteristics, both for the global sample as for the surgical subgroups. Univariate analysis of variance (ANOVA) and Chi-square tests were used to explore differences between subgroups. According to the recommendations of Hopwood et al. (2001), missing scores in one or two items of the BIS were replaced by the mean of the items to which participants had responded. Missing data on sociodemographic and clinical variables were low-level and random and therefore not substituted. A principal component analysis was performed to test the factor structure of the scale. To explore its internal consistency, Cronbach's alphas were obtained, as well as corrected item-total correlations and alpha values when the item was deleted. To explore the construct validity, Pearson's correlations between the BIS and other measures were calculated. To guard against inflated Type I errors, a Bonferroni correction was calculated taking into consideration the 10 hypothesized correlations, which indicated a more stringent significance level of $\alpha=.005$. Cohen's (1988) guidelines were used for describing the effect sizes of reported correlations (i.e. small for correlations around .10, medium for those near .30, and large for correlations at .50 or higher). To further analyse the discriminant validity of BIS, differences between types of surgeries were analysed through ANOVA. Eta squared $\left(\eta^{2}\right)$ was used as an estimate of the effect size. According to Cohen (1988, cit in Tabachnick and Fidell, 2007), values of $.01, .09$ and .25 were considered as small, medium and large effect sizes, respectively. 
Table 1

Demographic and clinical characteristics of the sample.

\begin{tabular}{|c|c|c|c|}
\hline & $\begin{array}{l}\text { Global sample } \\
n=173\end{array}$ & $\begin{array}{l}\text { Mastectomy } \\
\text { subgroup }^{\mathrm{a}} \\
n=122\end{array}$ & $\begin{array}{l}\text { BCS } \\
\text { subgroup }^{\mathrm{b}} \\
n=51\end{array}$ \\
\hline & $n(\%)$ & $n(\%)$ & $n(\%)$ \\
\hline \multicolumn{4}{|l|}{ Age (years) } \\
\hline$\leq 40$ & $15(9)$ & $11(9.3)$ & $4(8.2)$ \\
\hline $41-50$ & $50(29.9)$ & $36(30.5)$ & $14(28.6)$ \\
\hline $51-60$ & $65(38.9)$ & $44(37.3)$ & $21(42.9)$ \\
\hline $61-70$ & $34(20.4)$ & $24(20.3)$ & $10(20.4)$ \\
\hline$\geq 71$ & $3(1.8)$ & $3(2.5)$ & $0(0.0)$ \\
\hline Mean (SD); range & $\begin{array}{l}53.44(8.8) \\
32-81\end{array}$ & $\begin{array}{l}53.25(8.9) \\
33-81\end{array}$ & $\begin{array}{l}53.90(8.5) \\
32-68\end{array}$ \\
\hline \multicolumn{4}{|l|}{ Marital status } \\
\hline $\begin{array}{l}\text { Married or living with } \\
\text { someone }\end{array}$ & $130(75.1)$ & $91(74.6)$ & $39(76.5)$ \\
\hline $\begin{array}{l}\text { Divorced/single/ } \\
\text { widowed }\end{array}$ & $43(24.9)$ & $31(25.4)$ & $12(23.5)$ \\
\hline \multicolumn{4}{|l|}{ Education } \\
\hline Primary and basic school & $99(57.6)$ & $72(59.0)$ & 27 (52.9) \\
\hline High school & $27(15.7)$ & $16(13.1)$ & $11(21.6)$ \\
\hline College & $46(26.7)$ & $33(27.0)$ & $13(25.5)$ \\
\hline \multicolumn{4}{|l|}{ Socioeconomic status } \\
\hline Low & $53(30.8)$ & $39(32.0)$ & $14(27.5)$ \\
\hline Medium & $109(63.4)$ & $77(63.1)$ & $32(62.7)$ \\
\hline High & $10(5.8)$ & $5(4.1)$ & $5(9.8)$ \\
\hline \multicolumn{4}{|c|}{ Length of time since diagnosis ${ }^{c}$ (months) } \\
\hline Mean (SD); range & $\begin{array}{l}52.06(69.9) \\
2-384\end{array}$ & $\begin{array}{l}66.88(71.2) \\
2-384\end{array}$ & $\begin{array}{l}18.71(54.1) \\
2-366\end{array}$ \\
\hline \multicolumn{4}{|l|}{ Type of cancer } \\
\hline $\begin{array}{l}\text { Invasive ductal } \\
\text { carcinoma }\end{array}$ & $92(53.2)$ & $54(44.3)$ & $38(74.5)$ \\
\hline Ductal carcinoma in situ & $13(7.5)$ & $11(9.0)$ & $2(3.9)$ \\
\hline $\begin{array}{l}\text { Invasive lobular } \\
\text { carcinoma }\end{array}$ & $5(2.9)$ & $4(3.3)$ & $1(2.0)$ \\
\hline Lobular carcinoma in situ & $2(1.2)$ & $2(1.6)$ & $0(0.0)$ \\
\hline $\begin{array}{l}\text { Inflammatory breast } \\
\text { cancer }\end{array}$ & $5(2.9)$ & $4(3.3)$ & $1(2.0)$ \\
\hline Unknown & $56(32.3)$ & $47(38.5)$ & $9(17.6)$ \\
\hline \multicolumn{4}{|l|}{ Type of treatment ${ }^{\mathrm{d}}$} \\
\hline None & $26(15)$ & $24(19.7)$ & $2(3.9)$ \\
\hline Only chemotherapy & $49(28.3)$ & $42(34.4)$ & $7(13.7)$ \\
\hline Only radiotherapy & $33(19.1)$ & $13(10.7)$ & $20(39.2)$ \\
\hline $\begin{array}{l}\text { Chemotherapy and } \\
\text { radiotherapy }\end{array}$ & 57 (32.9) & $35(28.7)$ & $22(43.1)$ \\
\hline \multicolumn{4}{|l|}{ Axillary node dissection } \\
\hline Yes & $66(38.2)$ & $45(36.9)$ & $21(41.2)$ \\
\hline No & $101(58.4)$ & $74(60.7)$ & $27(52.9)$ \\
\hline \multicolumn{4}{|l|}{ Breast reconstruction } \\
\hline $\begin{array}{l}\text { Yes, already started the } \\
\text { process }\end{array}$ & $27(22.1)$ & $27(22.1)$ & - \\
\hline No & 95 (77.9) & 95 (77.9) & - \\
\hline
\end{tabular}

Note. The global sample is composed of two different surgical subgroups identified in the table as the "Mastectomy" subgroup and the "BCS" subgroup.

a Missing information on: education [1 $(0.9 \%)$ ], socioeconomic status [1 $(0.8 \%)$, type of treatment [7 (6.5\%)] and axillary node dissection [3 (2.4\%)].

b Missing information on: axillary node dissection [3 (5.9\%)].

c A significant difference between the surgical subgroups was found in the length of time since diagnosis $(p<.001)$.

${ }^{\mathrm{d}}$ A significant difference between the surgical subgroups was found in the type of treatment $(p<.001)$.

\section{Results}

\section{Participant's characteristics}

Participant's demographic/clinical characteristics are presented in Table 1 . At the time they participated in the study, 124 patients (71.7\%) were undergoing some sort of medical treatment (surgery or adjuvant treatment). The remaining 49 patients of the sample, although some treatment may have been done in the past, currently were not undergoing any kind of adjuvant treatment or surgery.

The surgical subgroups were similar in terms of the main demographic and clinical characteristics. Nevertheless, the ANOVA $[F(1$, $154)=17.45, p \leq .001, \eta^{2}=.10$ ] revealed that patients treated with BCS presented a lower mean time (mean $=18.7$ months, $\mathrm{SD}=54.1$ months) than those who had undergone mastectomy (mean $=66.9$ months, $\mathrm{SD}=71.2$ months). Additionally, as the chisquare test indicated, subgroups were also significantly different depending on the type of treatment $\left[\chi^{2}(3, N=165)=28.11, p \leq .001\right]$, with the majority of patients who had undergone mastectomy doing only chemotherapy and the majority of patients treated with BCS doing chemotherapy and radiotherapy (see Table 1 ).

\section{Principal component analysis}

To explore the factor structure of the Portuguese BIS, a principal component analysis (PCA) was performed on the entire sample. The appropriateness of factor analysis was verified by Keiser-MeyerOlkin (KMO) measure of sampling adequacy (.93) and Bartlett's test $(p<.001)$, both in favour of using this analysis. As on the original scale, the PCA revealed a single-factor solution with an eigenvalue of 6.12 , explaining $61.18 \%$ of the variance. The factor loadings ranged from .73 (item 10) to .90 (item 9).

\section{Reliability}

Cronbach's alpha revealed that the Portuguese BIS has adequate internal consistency, both in the total sample $(\alpha=.93)$, as in the subgroups of mastectomy ( $\alpha=.92)$ and BCS ( $\alpha=.93$ ).

In the global sample, corrected item-total correlations ranged from .47 to .86 . Most items did not increase the alpha value when deleted. The only exception was item 7 , which slightly increased the alpha when excluded (see Table 2).

\section{Convergent and discriminant validity}

To assess the convergent and discriminant construct validity of the Portuguese BIS, Pearson's correlations between this scale and measures of body image and QOL were computed. All the WHOQOL domains were analysed, as well as the specific facet of body image, included in the psychological domain (see Table 3 ).

Support for the convergent validity of the scale was demonstrated by associations with a large effect size $(>.50)$ between the BIS and the body shame subscale, the DAS24 and the body image facet of WHOQOL. Concerning appearance investment, a medium sized association was found between the BIS and the SES factor, but the association with the MS subscale was non-significant and very small. Moderate to large correlations were observed between the BIS and the WHOQOL domains.

The discriminant validity of the BIS was further assessed by comparing the BIS scores of patients who underwent mastectomy $(n=95)$ and those who underwent BCS $(n=51)$. Patients who had already started the process of reconstructive surgery were excluded from the analysis $(n=27)$. The ANOVA $[F(1,144)=21.02, p \leq .001$, $\left.\eta^{2}=.13\right]$ revealed that patients who underwent a mastectomy presented significantly more body image concerns $(M=10.70$; $\mathrm{SD}=8.07)$ than those treated with $\mathrm{BCS}(M=4.90 ; \mathrm{SD}=5.83)$. The effect size was considered medium (Cohen, 1988).

\section{BIS scores, age and time since diagnosis}

The association between age and BIS scores were non-significant and represented a small effect size $(r=.01, p=.93)$. Similarly, 
Table 2

Descriptives and item analysis.

\begin{tabular}{|c|c|c|c|c|}
\hline Item & $M(\mathrm{SD})$ & Range & Corrected item-total correlations & Alpha if item deleted \\
\hline \multicolumn{5}{|c|}{ 1. Have you been feeling self-conscious about your appearance? } \\
\hline Global sample & $0.82(0.91)$ & $0-3$ & .76 & .919 \\
\hline Mastectomy subgroup & $0.93(0.91)$ & $0-3$ & .74 & .909 \\
\hline BCS subgroup & $0.57(0.85)$ & $0-3$ & .83 & .921 \\
\hline \multicolumn{5}{|c|}{ 2. Have you felt less physically attractive as a result of your disease or treatment? } \\
\hline Global sample & $1.06(1.03)$ & $0-3$ & .75 & .919 \\
\hline Mastectomy subgroup & $1.22(1.07)$ & $0-3$ & .71 & .910 \\
\hline BCS subgroup & $0.69(0.81)$ & $0-3$ & .86 & .919 \\
\hline \multicolumn{5}{|c|}{ 3. Have you been dissatisfied with your appearance when dressed? } \\
\hline Global sample & $0.76(0.89)$ & $0-3$ & .71 & .922 \\
\hline Mastectomy subgroup & $0.85(0.92)$ & $0-3$ & .70 & .911 \\
\hline BCS subgroup & $0.55(0.78)$ & $0-3$ & .75 & .925 \\
\hline \multicolumn{5}{|c|}{ 4. Have you been feeling less feminine/masculine as a result of your disease or treatment? } \\
\hline Global sample & $0.59(0.87)$ & $0-3$ & .70 & .922 \\
\hline Mastectomy subgroup & $0.70(0.95)$ & $0-3$ & 69 & .911 \\
\hline BCS subgroup & $0.31(0.55)$ & $0-3$ & .73 & .928 \\
\hline \multicolumn{5}{|c|}{ 5. Did you find it difficult to look at yourself naked? } \\
\hline Global sample & $0.85(1.06)$ & $0-3$ & .77 & .918 \\
\hline Mastectomy subgroup & $1.06(1.12)$ & $0-3$ & .75 & .908 \\
\hline BCS subgroup & $0.35(0.69)$ & $0-3$ & .73 & .926 \\
\hline \multicolumn{5}{|c|}{ 6. Have you been feeling less sexually attractive as a result of your disease or treatment? } \\
\hline Global sample & $1.07(1.11)$ & $0-3$ & .72 & .922 \\
\hline Mastectomy subgroup & $1.28(1.15)$ & $0-3$ & .71 & .910 \\
\hline BCS subgroup & $0.57(0.83)$ & $0-3$ & .58 & .935 \\
\hline \multicolumn{5}{|c|}{ 7. Did you avoid people because of the way you felt about your appearance? } \\
\hline Global sample & $0.40(0.78)$ & $0-3$ & .47 & .932 \\
\hline Mastectomy subgroup & $0.48(0.83)$ & $0-3$ & .40 & .924 \\
\hline BCS subgroup & $0.22(0.61)$ & $0-3$ & .66 & .929 \\
\hline \multicolumn{5}{|c|}{ 8. Have you been feeling the treatment has left your body less whole? } \\
\hline Global sample & $1.10(1.08)$ & $0-3$ & .80 & .917 \\
\hline Mastectomy subgroup & $1.30(1.13)$ & $0-3$ & .77 & .906 \\
\hline BCS subgroup & $0.65(0.80)$ & $0-3$ & .73 & .921 \\
\hline \multicolumn{5}{|c|}{ 9. Have you felt dissatisfied with your body? } \\
\hline Global sample & $1.09(1.06)$ & $0-3$ & .86 & .913 \\
\hline Mastectomy subgroup & $1.32(1.08)$ & $0-3$ & .83 & .902 \\
\hline BCS subgroup & $0.53(0.79)$ & $0-3$ & .89 & .918 \\
\hline \multicolumn{5}{|c|}{ 10. Have you been dissatisfied with the appearance of your scar? } \\
\hline Global sample & $0.97(1.00)$ & $0-3$ & .67 & .924 \\
\hline Mastectomy subgroup & $1.18(1.06)$ & $0-3$ & .66 & .913 \\
\hline BCS subgroup & $0.47(0.61)$ & $0-3$ & .54 & .940 \\
\hline \multicolumn{5}{|l|}{ Overall BIS } \\
\hline Global sample & $8.72(7.67)$ & $0-29$ & - & - \\
\hline Mastectomy subgroup & $10.3(7.81)$ & $0-29$ & - & - \\
\hline BCS subgroup & $4.90(5.83)$ & $0-21$ & - & - \\
\hline
\end{tabular}

a non-significant and weak association was found between the length of time since diagnosis and the BIS scores, $(r=.02, p=.78)$.

\section{Discussion}

The aim of this study was to investigate the psychometric properties of the Portuguese version of the body image scale on a sample of breast cancer patients. It replicated and extended previous findings to the original scale, demonstrating that the Portuguese BIS, like the original, is a psychometrically sound measure for the assessment of body image concerns of breast cancer patients and that it is appropriate for use in clinical and research settings.

Our factor analysis confirmed the original single-factor structure, also explaining a great amount of variance $(57.55 \%$ in the original study). Due to our lower number of participants and contrary to the original study, in which a factor analysis was performed both on the total sample and on surgical subgroups, we chose to conduct a factor analysis only on the global group of women with breast cancer.
Although the authors have found a two-factor solution in the subsample of patients treated with mastectomy, they considered this result irreproducible, adopting the single solution, found in all the other groups, as the final one (Hopwood et al., 2001).

The Portuguese version of the BIS demonstrated a good internal consistency. The reliability coefficients, both for the global sample as for the surgical subgroups, were quite similar to those reported for the original BIS (i.e. .91 for both patients treated with mastectomy and BCS and .93 for the global sample). The internal consistency of the scale was also confirmed by the item-total correlations, all above the usual criteria of .30 (Field, 2005), which indicates that all items correlate well with the total scale score and measure the same construct. Moreover, almost all alpha values for each item (when they are deleted) were lower than the overall alpha, indicating that its deletion would not contribute to an increase of the overall reliability. The only exception was item 7 (Did you avoid people because of the way you felt about your appearance?), although its deletion only slightly improved the scale's overall reliability. This item was retained, not only because it had an adequate item-total correlation but also to 
Table 3

Correlations between BIS and other measures of body image and QOL.

\begin{tabular}{lc}
\hline Measures & BIS \\
\hline Body Shame subscale & $.68^{*}$ \\
DAS24 & $.75^{*}$ \\
ASI-R & $.40^{*}$ \\
SES & -.12 \\
MS & \\
WHOQOL & $-.42^{*}$ \\
Physical & $-.49^{*}$ \\
Psychological & $-.34^{*}$ \\
Social relationships & $-.40^{*}$ \\
Environment & $-.52^{*}$ \\
General facet & $-.66^{*}$ \\
Body image facet & .01 \\
Age & .02 \\
Length of time since diagnosis & \\
\hline${ }^{*} p<.001$ &
\end{tabular}

ensure the maximum compatibility between the Portuguese and English versions and to maximize the content validity of the scale.

Considering the possible range of scores, both for each item $(0-3)$ as for the global scale $(0-30)$, the results obtained were, in general, low, although comparable to those presented in the original study. These results could be a reflection of social desirability, as some patients could be embarrassed and have difficulty in admitting their concerns about their physical appearance when facing a disease such as breast cancer. Also, the use of doublenegative questions could be confusing in some way, thus preventing the use of the fully possible range of response values.

Evidence for the construct validity of the Portuguese BIS was provided. As it was hypothesized, a strong relationship between the BIS and other measures of body image was found. Particularly, the BIS strongly correlated with the body shame subscale, the overall DAS24 and the body image facet of psychological QOL domain, which suggests that this measure covers issues such as body shame, self-consciousness of appearance or global satisfaction with physical appearance, as originally intended. Also as expected, the association with SES factor of ASI-R was moderate in magnitude since these two instruments actually measure different (yet related) aspects of body image. This finding is consistent with other studies that have demonstrated that women who tend to base their self-worth and self-esteem on their appearance (i.e. those who invest more), also tend to be more concerned with their body image (Cash et al., 2004; Jakatdar et al., 2006). However, contrary to our expectations, the association with the MS factor was non-significant and small in magnitude. Concerning the pattern of associations between the BIS scores and the WHOQOL domains and general facet, our initial hypothesis was partially confirmed as our findings showed medium to large correlations between them. This calls our attention to the importance that body image has on a patient's QOL and is consistent with previous findings showing that more concerns with appearance are related to lower levels of QOL (e.g. DeFrank et al., 2007). This pattern of associations supports the construct validity of the Portuguese BIS.

In further support of the discriminant validity of this instrument, women who underwent mastectomy scored significantly higher on the scale than those who underwent BCS. This supports the utility of the BIS for differentiating surgery groups characterized by different appearance changes. This finding is in line with previous research (Bloom et al., 1998; Fallowfield et al., 1986; Kiebert et al., 1991; Yilmazer et al., 1994) and also with the results of Hopwood et al. (2001).

Contrary to the results obtained in the original study (Hopwood et al., 2001), which demonstrated that younger women had more body image concerns, our findings did not show an association between age and BIS scores, as we expected. Although the effect of age on a patients' body image has been addressed in a number of studies, the results are inconsistent, with some data demonstrating more body image concerns among younger breast cancer patients (e.g. Hopwood et al., 2001; Moyer, 1997; Levy et al., 1992; Romanek et al., 2005) and others not finding any effect of age on body image (e.g. Manos et al., 2005). Similarly, time since diagnosis did not correlate significantly with body image concerns, also contrary to the results of Hopwood et al. (2001), which found higher scores after 6 months from the time of first surgery. Research on this matter is not consistent, as some studies indicate a better body image soon after diagnosis and a worsening with time (Bloom et al., 1998; Hartl et al., 2003), others report a significant improvement in body image over time (Arora et al., 2001; Ganz et al., 1992b) and others demonstrate a stability on body image through the disease (DeFrank et al., 2007). This inconsistency may be due to the different measures of body image that were used and not to the real effect of time. It is also important to note that the cross-sectional design of the present study limits conclusions about the influence of this variable.

Some limitations of this study should be considered when interpreting the results. Firstly, the absence of longitudinal data made the examination of the temporal stability of the scale impossible, which would add support for its reliability. Future longitudinal research is needed to examine the test-retest reliability of the Portuguese BIS and also to further explore the influence of time since diagnosis on body image. Secondly, the majority of patients had undergone a mastectomy, therefore not allowing for the examination of the BIS's factor structure among different surgery groups, i.e. the examination of the factor structure both for patients that had undergone mastectomy and those that had received BCS, as analysed by Hopwood et al. (2001). Future studies should include a larger sample, comprised of an equivalent number of patients treated with mastectomy and BCS, in order to provide further information about the factor structure of the BIS in these two different surgical groups. Thirdly, the impossibility of consulting the medical records of the participants recruited from the Reach to Recovery Association made it difficult to assess demographic/clinical data, which resulted in some missing information. Future research is also needed to confirm the unidimensionality and the psychometric performance of the BIS in other cancer populations.

In summary, the Portuguese version of BIS proved to be a psychometrically robust self-report measure of body image concerns on a sample of breast cancer patients. Its brevity and comprehensibility allow a rapid and clear assessment, both on clinical and research settings, complementing the QOL measurement of cancer patients, when body image is an important outcome. This could be an important assessment tool for nurses that work with cancer patients, as it provides a brief and clear assessment of body image issues of cancer patients. Nurses, who are one of health care's professional groups that have closer and more regular contact with patients in all stages of the disease, play an important role in helping patients deal with present or anticipated appearance changes. With a comprehensive assessment they can more easily identify areas of concern and help patients to deal with several aspects such as feelings of shame and loss of selfworth and self-esteem, problems in the decision making process about surgery, difficulties in adjusting to appearance change, among many others. Their role can be particularly relevant, for instance, in the preparation of surgical or medical interventions and also in the prevention of psychological difficulties following an anticipated threat of body image, such as mastectomy or chemotherapy-induced alopecia.

\section{Conflict of interest statement}

No conflicts of interest exist for any of the authors of this study. 


\section{Appendix 1}

\section{Escala de Imagem Corporal - BIS}

Relações,

\section{Desenvolvimento \&}

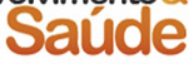

Relationships, Development \& Health

Versão original: P. Hopwood (2000);

Versão Portuguesa: H. Moreira \& M.C. Canavarro (2007)

Neste questionário ser-lhe-ão colocadas algumas questões acerca da forma como se sente em relação ao seu corpo e acerca de algumas mudanças que podem ter ocorrido como resultado da sua doença e dos tratamentos a que foi submetido(a).

Por favor, leia cada questão cuidadosamente e assinale a resposta que considerar mais adequada e que melhor corresponder à forma como se tem sentido na última semana.

\begin{tabular}{|c|c|c|c|c|c|}
\hline & & Nada & $\begin{array}{c}\text { Um } \\
\text { Pouco }\end{array}$ & Moderamente & Muito \\
\hline 1 & $\begin{array}{l}\text { Tem-se sentido constrangido(a) ou inibido(a) com } \\
\text { a sua aparência? }\end{array}$ & 0 & 1 & 2 & 3 \\
\hline 2 & $\begin{array}{l}\text { Sentiu-se menos atraente fisicamente devido à } \\
\text { doença e ao tratamento? }\end{array}$ & 0 & 1 & 2 & 3 \\
\hline 3 & $\begin{array}{l}\text { Tem-se sentido insatisfeito(a) com a sua aparência } \\
\text { quando está vestido(a)? }\end{array}$ & 0 & 1 & 2 & 3 \\
\hline 4 & $\begin{array}{l}\text { Tem-se sentido menos masculino/feminina por } \\
\text { causa da doença ou do tratamento? }\end{array}$ & 0 & 1 & 2 & 3 \\
\hline 5 & Teve dificuldade em olhar para o seu corpo, nu(a)? & 0 & 1 & 2 & 3 \\
\hline 6 & $\begin{array}{l}\text { Tem-se sentido menos atraente sexualmente } \\
\text { como resultado da sua doença ou tratamento? }\end{array}$ & 0 & 1 & 2 & 3 \\
\hline 7 & $\begin{array}{l}\text { Evitou encontrar-se com pessoas devido à forma } \\
\text { como se sentia em relação à sua aparência? }\end{array}$ & 0 & 1 & 2 & 3 \\
\hline 8 & $\begin{array}{l}\text { Tem sentido que o tratamento deixou o seu corpo } \\
\text { "menos completo"? }\end{array}$ & 0 & 1 & 2 & 3 \\
\hline 9 & Sentiu-se insatisfeito(a) com o seu corpo? & 0 & 1 & 2 & 3 \\
\hline 10 & $\begin{array}{l}\text { Tem-se sentido insatisfeito(a) com a aparência da } \\
\text { sua cicatriz? }\end{array}$ & 0 & 1 & 2 & 3 \\
\hline
\end{tabular}

Contactos: Helena Moreira, Linha de investigação Relações, Desenvolvimento \& Saúde, do Instituto de Psicologia Cognitiva e Desenvolvimento Vocacional e Social (IPCDVS) da Faculdade de Psicologia e Ciências da Educação da Universidade de Coimbra, Portugal. helena.tcmoreira@gmail.com 


\section{References}

Aaronson, N., Ahmedzai, S., Bergman, B., Bullinger, M., Cull, A., Duez, N., Filiberti, A., Flechtner, H., Fleishman, S.B., de Haes, J.C., et al., 1993. The European Organization for Research and Treatment of Cancer QLQ-C30: a quality-of-life instrument for use in international clinical trials in oncology. Journal of National Cancer Institute 85 (5), 365-376.

Andrews, B., Qian, M., Valentine, J., 2002. Predicting depressive symptoms with a new measure of shame: the Experience of Shame Scale. British Journal of Clinical Psychology 41, 29-42.

Arora, N., Gustafson, D., Hawkins, R., McTavish, F., Cella, D., Pingree, S., et al., 2001 Impact of surgery and chemotherapy on the quality of life of younger women with breast carcinoma: a prospective study. Cancer 92, 1288-1298.

Baxter, N., Goodwin, P., McLeod, R., Dion, R., Devins, G., Bombardier, C., 2006. Reliability and validity of the Body Image after Breast Cancer Questionnaire. The Breast Journal 12 (3), 221-232.

Bloom, J., Stewart, S., Johnston, M., Banks, P., 1998. Intrusiveness of illness and quality of life in young women with breast cancer. Psycho-Oncology 7, 89-100.

Bloom, J., Kang, S., Petersen, D., Stewart, S., 2007. Quality of life in long-term cancer survivors. In: Feuerstein, M. (Ed.), Handbook of Cancer Survivorship. Springer, New York, pp. 43-63.

Carr, T., Harris, D., James, C., 2000. The Derriford Appearance Scale (DAS59): a new scale to measure individual responses to living with problems of appearance. British Journal of Health Psychology 5, 201-215.

Carr, T., Moss, T., Harris, D., 2005. The DAS24: a short form of the Derriford Appearance Scale DAS59 to measure individual responses to living with problems of appearance. British Journal of Health Psychology 10, 285-298.

Carver, C., Pozo-Kaderman, C., Price, A., Noriega, V., Harris, S., Derhagopian, R., Robinson, D.S., Moffat, F.L., 1998. Concern about aspects of body image and adjustment to early stage breast cancer. Psychosomatic Medicine 60, 168-174.

Cash, T., Pruzinsky, T., 1990. Body Images: Development, Deviance, and Change. Guilford Press, New York.

Cash, T., Pruzinsky, T., 2002. Body image: A Handbook of Theory, Research, and Clinical Practice. Guilford Press, New York.

Cash, T., Melnyk, S., Hrabosky, J., 2004. The assessment of body image investment: an extensive revision of the Appearance Schemas Inventory. International Journal of Eating Disorders 35, 305-316.

Cohen, J., 1988. Statistical Power Analysis for the Behavioural Sciences, second ed. Academic Press, New York.

Cull, A., Sprangers, M., Bjordal, K., Aaronson, N., 2002. EORTC Quality of Life Study Group Translation Procedure. EORTC Quality of Life Study Group.

DeFrank, J., Mehta, C., Stein, K., Baker, F., 2007. Body image dissatisfaction in cancer survivors. Oncology Nursing Forum 34 (3), 625-631.

Fallowfield, L., Baum, M., Maguire, G., 1986. Effects of breast conservation on psychological morbidity associated with diagnosis and treatment of early breast cancer. British Medical Journal 293, 1331-1334.

Field, A., 2005. Discovering Statistics using SPSS, second ed. Sage Publications, London.

Frith, H., Harcourt, D., Fussell, A., 2007. Anticipating an altered appearance: women undergoing chemotherapy treatment for breast cancer. European Journal of Oncology Nursing 11, 385-391.

Ganz, P., Lee, J., Sim, M., Polinsky, M., Schag, C., 1992b. Exploring the influence of multiple variables on the relationship of age to quality of life in women with breast cancer. Journal of Clinical Epidemiology 45 (5), 473-485.

Ganz, P., Schag, A., Lee, J., Polinsky, M., Tan, S., 1992a. Breast conservation versus mastectomy: is there a difference in psychological adjustment or quality of life in the year after surgery? Cancer 69, 1729-1738.

Ganz, P., Schag, C., Lee, J., Sim, M., 1992c. The CARES: a generic measure of health-related quality of life for patients with cancer. Quality of Life Research 1 (1), 19-29.

Hartl, K., Janni, W., Kastner, R., Sommer, H., Strobl, B., Rack, B., et al., 2003. Impact of medical and demographic factors on long-term quality of life and body image of breast cancer patients. Annals of Oncology 14, 1064-1071.

Helms, R., O'Hea, E., Corso, M., 2008. Body image issues in women with breast cancer. Psychology, Health \& Medicine 13 (3), 313-325.
Hormes, J., Lytle, L., Gross, C., Ahmed, R., Troxel, A., Schmitz, K., 2008. The body image and relationships scale: development and validation of a measure of body image in female breast cancer survivors. Journal of Clinical Oncology 26 (8), 1269-1274.

Hopwood, P., Fletcher, I., Lee, A., Al Ghazal, S., 2001. A body image scale for use with cancer patients. European Journal of Cancer 37, 189-197.

Jakatdar, T., Cash, T., Engle, E., 2006. Body-image thought processes: the development and initial validation of the Assessment of Body-Image Cognitive Distortions. Body Image 3, 325-333.

Janz, N., Mujahid, M., Lantz, P., Fargelin, A., Salem, B., Morrow, M., Deapen, D., Katz, S.J., 2005. Population-based study of the relationship of treatment and sociodemographics on quality of life for early stage breast cancer. Quality of Life Research 14, 1467-1479.

Kiebert, G., deHaes, J., van de Velde, C., 1991. The impact of breast-conserving treatment and mastectomy on the quality of life of early stage breast cancer patients: a review. Journal of Clinical Oncology 9, 1059-1070.

Levy, S., Haynes, L., Herberman, R., Lee, J., McFeele, S., Kirkwood, J., 1992. Mastectomy versus breast conservation surgery: mental health effects at long-term follow-up. Health Psychology 11 (6), 349-354.

Manos, D., Sebastián, J., Bueno, M., Mateos, N., Torre, A., 2005. Body image in relation to self-esteem in a sample of Spanish women with early-stage breast cancer. Psicooncología 2 (1), 103-116.

Moyer, A., 1997. Psychosocial outcomes of breast-conserving surgery versus mastectomy: a meta-analytic review. Health Psychology 16 (3), 284-298.

Nazaré, B., Moreira, M., Canavarro, M.C., in press. Uma perspectiva cognitivo-comportamental sobre o investimento esquemático na aparência: Estudos psicométricos do Questionário de Crenças sobre a Aparência (ASI-R) [A cognitive-behavioral perspective on schematic investment in appearance: Psychometric studies of The Beliefs About Appearance Questionnaire (ASI-R)]. Laboratório de Psicologia.

Poulsen, B., Graversen, H., Beckmann, J., Blichert-Toft, M., 1997. A comparative study of post-operative psychosocial function in women with primary operable breast cancer randomized to breast conservation therapy or mastectomy. European Journal of Surgical Oncology 23, 327-334.

Romanek, K., McCaul, K., Sandgren, A., 2005. Age differences in treatment decision making for breast cancer in a sample of healthy women: the effects of body image and risk framing. Oncology Nursing Forum 32 (4), 799-806.

Rumsey, N., Harcourt, D., 2005. The Psychology of Appearance. Open University Press, New York.

Sprangers, M., Cull, A., Bjordal, K., Groenvold, M., Aaronson, N., 1993. The European Organization for Research and Treatment of Cancer approach to quality of life assessment: guidelines for developing questionnaire modules. Quality of Life Research 2 (4), 287-295.

Tabachnick, B., Fidell, L., 2007. Using Multivariate Statistics. Allyn and Bacon, Boston.

Vaz Serra, A., Canavarro, M.C., Simões, M.R., Pereira, M., Quartilho, M., Rijo, D. Carona, C., Paredes, T., 2006. Estudos psicométricos do instrumento de avaliação da qualidade de vida da Organização Mundial de Saúde (WHOQOL-Bref) para Português de Portugal [Psychometric studies of the World Health Organization Quality of Life Assessment (WHOQOL-Bref) for Portuguese from Portugal]. Psiquiatria Clínica 27 (2), 41-49.

Victorson, D., Cella, D., Wagner, L., Kramer, L., Smith, M., 2007. Measuring quality of life in cancer survivors. In: Feuerstein, M. (Ed.), Handbook of Cancer Survivorship. Springer, New York, pp. 79-110.

White, C., 2000. Body image dimensions and cancer: a heuristic cognitive behavioural model. Psycho-Oncology 9 (3), 183-192.

White, C., 2002. Body images in oncology. In: Cash, T., Pruzinsky, T. (Eds.), Body Image: A Handbook of Theory, Research, and Clinical Practice. The Guilford Press, New York, pp. 379-386.

WHOQOL Group, 1998a. The World Health Organization Quality of Life Assessment (WHOQOL): development and general psychometric properties. Social Science \& Medicine 46 (12), 1569-1585.

WHOQOL Group, 1998b. Development of the World Health Organization WHOQOLBREF Quality of Life Assessment. Psychological Medicine 28, 551-558.

Yilmazer, N., Aydiner, A., Ozkan, S., Aslay, I., Bilge, N., 1994. A comparison of body image, self-esteem and social support in total mastectomy and breastconserving therapy in Turkish women. Supportive Care in Cancer 2, 238-241. 